\title{
Visual analysis of ICC themes and topics from 2009 to 2019
}

\author{
LI Jing $^{\text {a }}$, LIU Haiyan ${ }^{\text {a }}$ KANG Lei ${ }^{\text {a }}$ \\ ${ }^{a}$ Institute of Surveying and Mapping in Zhengzhou,351800040@qq.com
}

Keywords: ICC, visual analysis, themes and topics, hotspots

\begin{abstract}
:
The themes and topics of the conference reflect the hot issues of the conference. The change of conference theme reflects the development and change of the hot topics of discipline research from the side. This paper uses bibliometrics to quantitatively analyze the topics and topics of International Cartographic Conference (ICC) from 2009 to 2019 , and presents them through visualization methods such as label clouds, charts and so on.

The research mainly includes three aspects: 1. Fixed topic analysis refers to the analysis of topics in past years, which can reflect the core content of ICC; 2. High-frequency topic analysis refers to the analysis of topics with high frequency, which can reflect hot topics of general concern; 3. Sudden topic analysis refers to the division of topics with sudden increase in short time. The analysis can reflect the research content with high heat in a short time. From the perspective of text analysis, this study analyzed the conference topics, which reflected the development and research changes of Cartography in the ten years, and provided some references for our experts in their research.
\end{abstract}

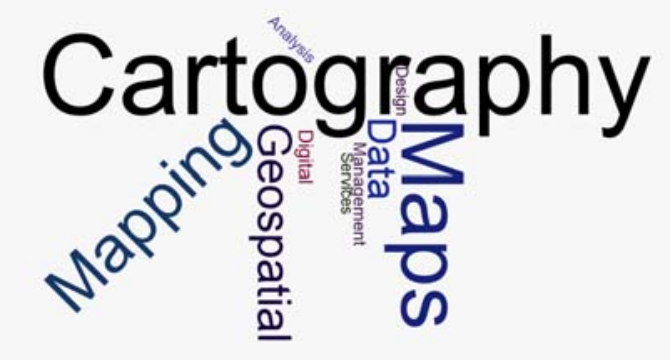

Figure 1. Word-Cloud for High Frequency Key Words in themes and topics.

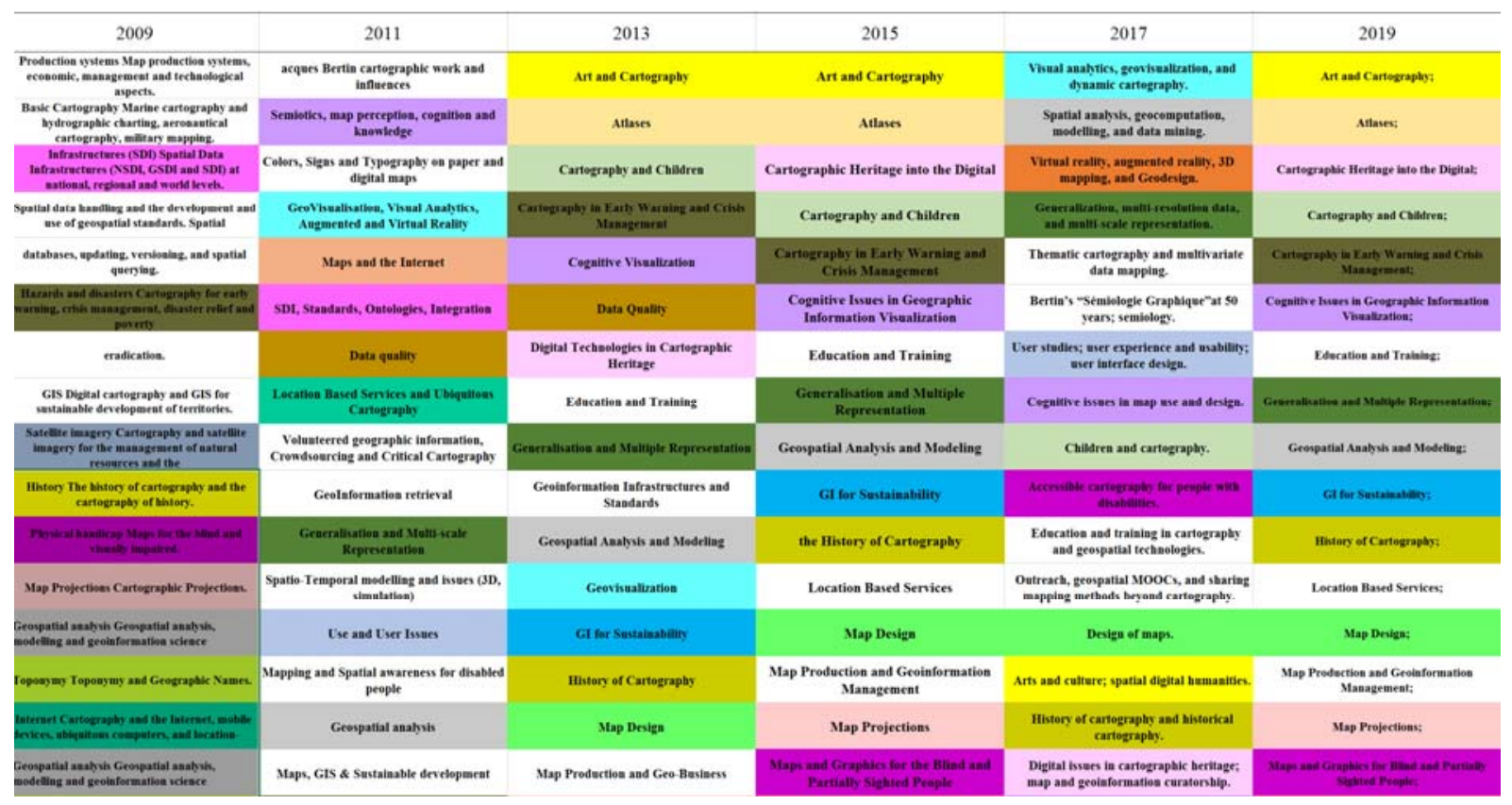

Figure 2. List of themes and topics for 2009-2019 in ICC. (part) 